\title{
Method First, Results Later
}

\author{
BY TOM GARRISON
}

About ten years ago I participated in the first of a series of workshops sponsored by the National Science Foundation to determine ideal course content for a college undergraduate student's first class in marine science. A few years later I was lucky to be present at the birth of COSEE (Centers for Ocean Science Education Excellence), the preeminent organization for influencing teacher training in the marine sciences. This last June it was my pleasure to be a team leader for the CORE (Consortium for Oceanographic Research and Education) subcommittee charged with the responsibility of suggesting what oceanic knowledge should be presented to the general public. I have spent much time thinking about our field and how it might be represented to the folks who pay the bills.

In each of these instances, when the responsibility sinks in and one is left alone with one's thoughts, a few givens leap into clear view. First, not surprisingly, is the nature of the audience. Though an increasing number are "free choice learners"-people who stop clicking channels when they encounter something oceanic, visit public aquaria, scan marine web sites, and read newspaper articles on recent discoveries - most of the public is incurious and believes research results are controversial and difficult to comprehend. These science skep- tics are not necessarily wary of the results of scientific inquiry (they love their iPods and cellular telephones), but believe the general reasoning underlying them is just too hard to master. They often misinterpret minor disagreements between specialists as an indictment of an entire field. Worse, they are particularly susceptible to "argument from authority," the willingness to believe the loudest and most persistent voice. We can thank this last tendency for the growing debacle of "intelligent design" and other wonders. ${ }^{1}$

We should not begin our interactions with the public with stories or results. Our starting place must always be the nature of scientific inquiry. Like other sciences, marine science is based in curiosity. In particular, the question "how do we know?" is vital to an understanding of the natural world. We arrive at tentative explanations for the features and processes of things we can see, feel, touch, and hear by a systematic way of asking and answering questions about the natural world. As we begin thinking about how to represent our field, we must keep in mind the scientific logic that underpins the objects and ideas we will discuss. We need to explain that science is a systematic process of asking questions about the observable world by gathering and then studying information (data), but explain that the information itself is not science. Science interprets raw information by constructing a general explanation with which the information is compatible.

We should note that theories and laws in science do not arise fully formed or all at once. Scientific thought progresses as a continuing chain of questioning, testing, and matching theories to observations. A theory is strengthened if new facts support it. If not, the theory is modified or a new explanation is sought. The power of science lies in the ability of the process to operate in reverse; that is, in the use of a theory or law to make predictions and anticipate new facts to be observed.

This procedure (we often call it the scientific method) is an orderly process by which theories are verified or rejected. It is based on the assumption that nature "plays fair" — that the rules governing natural phenomena do not change capriciously as our powers of questioning and observing improve. We believe that the answers to our questions about nature are ultimately knowable.

The public is often astonished that nothing is ever proven absolutely true by the scientific method. Theories may

Tom Garrison (tomgarrison@sbcglobal. net) is an instructor at Orange Coast College, Costa Mesa, CA, USA. 
change as our knowledge and powers of observation change; thus all scientific understanding is tentative. Science is neither a democratic process nor a popularity contest. The conclusions about the natural world that we reach by the process of science may not always be comfortable, easily understood, or immediately embraced, but if those conclusions consistently match observations, they may be considered true.

Now it's time to show some of the results of the scientific process as it has been applied to the world ocean. We presents facts, interpretations of facts, examples, stories, and some of the crucial discoveries that have led to our present understanding of the ocean and the planet on which it formed. As the results of science change, so will the ideas and interpretations we present.

Our job is made easier by the natural enthusiasm the public brings to their study of this field. Even the most distracted listener will perk up when presented with stories of encounters with huge waves, photos of giant squids, tales of exploration under the best and worst of circumstances, evidence that vast chunks of Earth's surface slowly move, news of Earth's past battering by asteroids, micrographs of glistening diatoms, and data showing the growing economic importance of seafood and marine materials. If pure spectacle is required to generate an initial interest in the study of science, oceanography wins hands down!

So, there is an exciting story to tell. How? The ideal plan is straightforward: We should begin with a look at origins. Because all matter on Earth, except hydrogen and some helium, was generated in stars, our story of the ocean necessar- ily starts with stars. Have oceans evolved elsewhere? Next we can discuss the history of marine science. When was Earth's age figured out? Theories of Earth structure and plate tectonics might be presented next as a base on which to build the explanation of bottom features that follow. What is the shape of the ocean floor? A survey of ocean physics and chemistry prepares us for discussions of atmospheric circulation, classical physical oceanography, and coastal processes. Our look at marine biology could begin with an overview of the problems and benefits of living in seawater, continue with a discussion of the production and consumption of food, and end with taxonomic and ecological surveys of marine organisms. The last segments would treat marine resources and an ugly bunch of environmental concerns. rine sediments on the deep seabed must be aware of the biology and life histories of the organisms in the water above, the chemistry that affects the shells and skeletons of the creatures as they fall to the ocean floor, the physics of particle settling and water density and ocean currents, and the age and underlying geology of the study area. Our presentations should be organized to make those connections from the outset.

Now imagine you've received an email asking you to discuss your specialty with a Boy Scout group, your daughter's $8^{\text {th }}$ grade science class, or the Rotary Club. First, agree to go! Next, think about ways to make your studies applicable to the listeners' everyday lives. (Movies like The Core and The Day After Tomorrow, ghastly though they were, piqued the public's interest-they won-

\section{${ }^{1}$ As I write (June 2005), the New York Times reports that 12 publicly supported museums and other institutions in}

the American southeast have agreed not to show the IMAX films “Cosmic Voyage," “The Galapagos,” and "Volcanoes of the Deep Sea" because viewers at test screenings judged

\section{films that discuss general evolution and contradict religious descriptions of man's origins as "blasphemous." What does this tell us about the state of science education in America? Clearly, we have much work to do.}

\section{Connections between disciplines} should be emphasized throughout. Marine science draws on several fields of study, integrating the work of specialists into a unified whole. For example, a geologist studying the composition of ma- der “Could that happen?") Now let your enthusiasm carry you through. Explain how science proceeds before showing results. Show connections. Be courageous! Your science will speak for itself! 四 